\title{
Polymer Flow Influenced by Mold Cavity Surface Roughness
}

\author{
Michal Stanek, Miroslav Manas, Martin Ovsik, Martin Reznicek, Vojtech Senkerik, Vaclav Janostik \\ Tomas Bata University in Zlin.Nam. T.G. Masaryka 5555, 76001 Zlin. Czech Republic.E-mail: stanek@utb.cz
}

Polymer injection molding is the most used technology of polymer processing nowadays. It enables the manufacture of final products, which do not require any further operations. Working of shaping cavities is the major problem involving not only the cavity of the mold itself, giving the shape and dimensions of the future product, but also the flow pathway (runners) leading the polymer melt to the separate cavities. This paper shows the influence of cavity surface roughness, polymer material (with different flow properties) and technological parameters on the flow length of polymers into mold cavity. Application of the measured results may have significant influence on the production of shaping parts of the injection molds especially in changing the so far used processes and substituting them by less less expensive production processes which might increase the competitiveness of the tool producers and shorten the time between product plan and its implementation.

Keywords: Injection Molding, Surface Roughness, Polymer, Fluidity, Tools

\section{Introduction}

Imolding is one of the most extended polymer processing technologies. It enables the manufacture of final products, which do not require any further operations. The tools used for their production - the injection molds - are very complicated assemblies that are made using several technologies and materials. The correct function of shaping cavities cavities is the major problem involving not only the cavity of the mold itself, giving the shape and dimensions of the future product, but also the flow pathway (runners) leading the polymer melt to the separate cavities. In practice, high quality of runner surface is still very often required. Hence surface polishing for perfect conditions for melt flow is demanded. The aformentioned finishing operations are very time and money consuming leading to high costs of the tool production. The fluidity of all polymers during injection molding cycle is affected by many parameters (mold design, melt temperature, mold temperature, injection rate, pressures, etc.) and by the flow properties of polymers. Results of the experiments carried out with selected types of polymer materials proved a minimal influence of surface roughness of the runners on the polymer melt flow. This considers excluding (if the conditions allow it) the very complex and expensive finishing operations from the technological process as the influence of the surface roughness on the flow characteristics does not seem to play as important role as was previously thought. A plastic nucleus is formed by the way of laminar flow, which enables the compression of the melt in the mold and consecutive creeping.

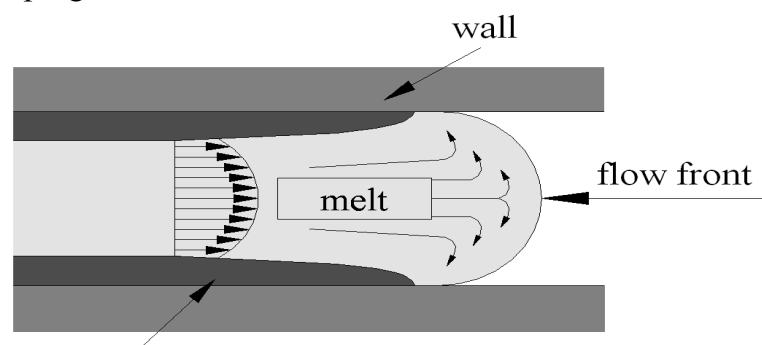

solidifying layer

Fig. 1 Fountain flow
A constant flow rate given by the axial movement of the screw is chosen for most of the flows. During filling of the mold cavity the plastic material does not slide along the steel mold surface but it is rolled over. This type of laminar flow is usually described as a "fountain flow" (Fig.1).

\section{Injection molding technology}

The testing samples were prepared by injection molding technology. The injection mold for this task was designed to have easiest possible manipulation both with the mold itself and during injection molding process while changing the testing plates, size of the mold gate, pressure and temperature sensors inside the cavity, etc. The cavity space of the mold is generated by the female mold part, called cavity, and a male mold part, called the core. It is necessary to fill the mold cavity fully during the injection molding process. The ability of cavity filling could be affected by the polymer properties and the properties of cavity walls. The shaping part of the injection mold is composed of right and left side. The most important parts of the injection mold concerning the measurements are: testing plate, cavity plate and a special sprue puller insert. It is possible to use pressure and temperature sensors in the mold cavity to evaluate the values progress.

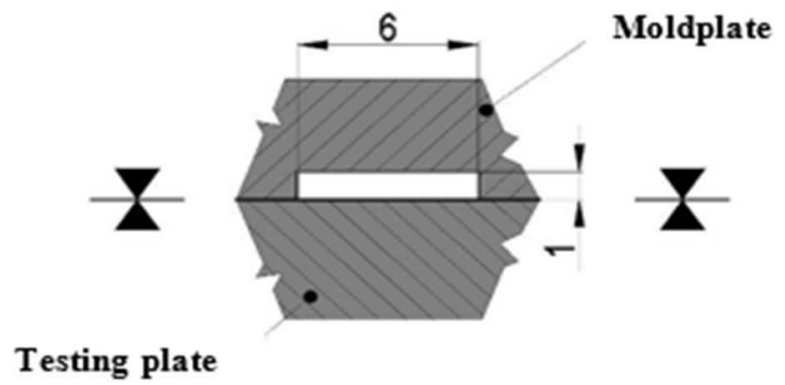

Fig. 2 Cross section of mold cavity

The cavity (Fig. 5) of testing injection mold is in a shape of a spiral with the maximum possible length of $2000 \mathrm{~mm}$ and dimensions of channel cross-section: 6x1 $\mathrm{mm}$. The cavity is created when the injection mold is closed, i.e. when shaping plate seals the testing plate in the 
parting plane of the mold. The mold cavity is cooled by flowing oil from tempering unit. [2]

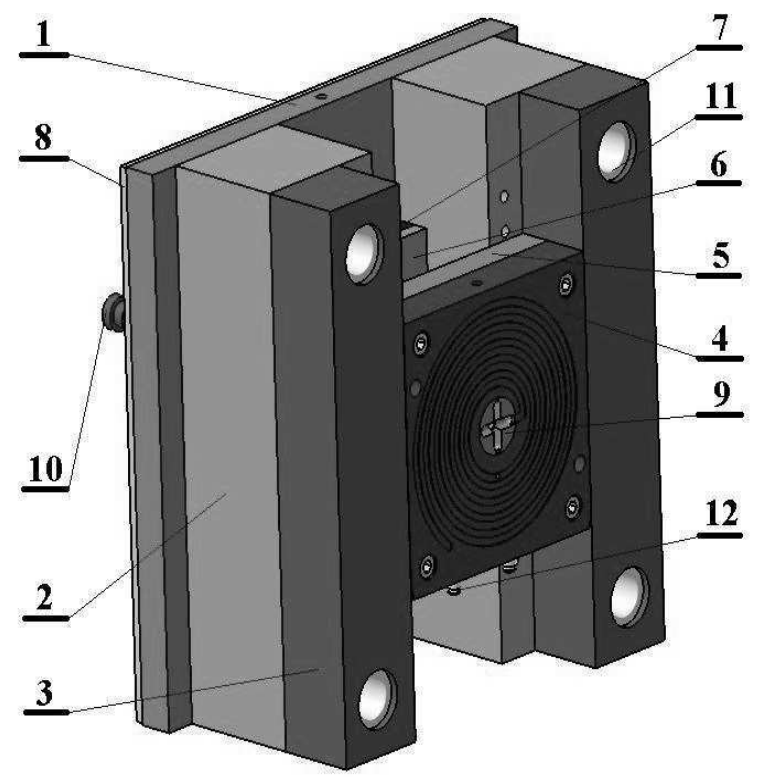

a) Right side of injection mold (ejection side) 1 -clamping plate, 2, 3-spacer plate, 4 -cavity plate, 5 - plate, 6,7-ejector plates, 8 - insulating plate, 9 sprue puller insert, 10 - ejector rod, 11 -guide bush, 12 - hose nipple

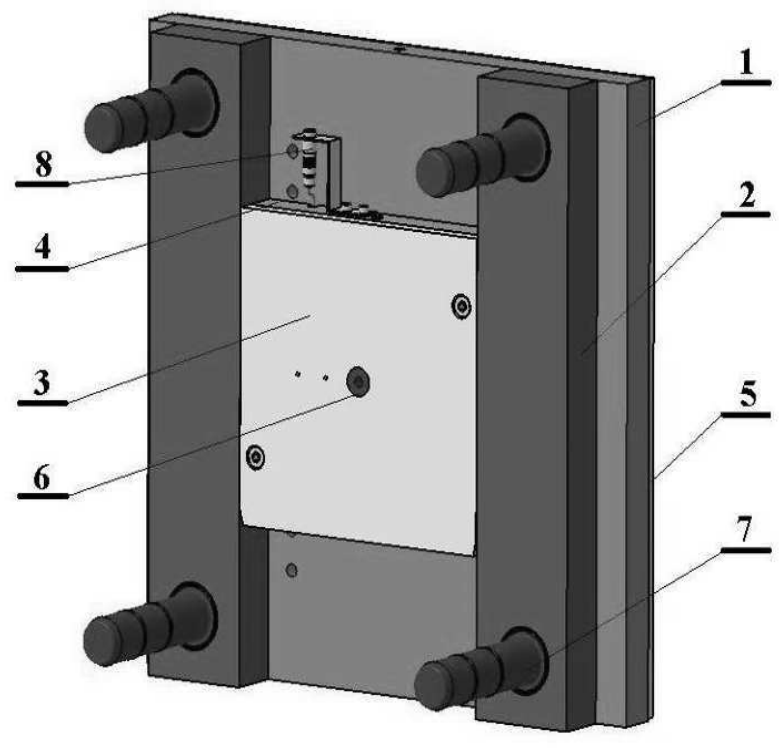

b) Left side of injection mold (sprue side)

1 - clamping plate, 2 -spacer plate, 3 -testing plate, 4 - plate, 5 - insulating plate, 6 - sprue bushing, 7 guide pillar, 8 - connector of pressure sensor

Fig. 3 Injection mold

Tab. 1 Surfaces of testing plates

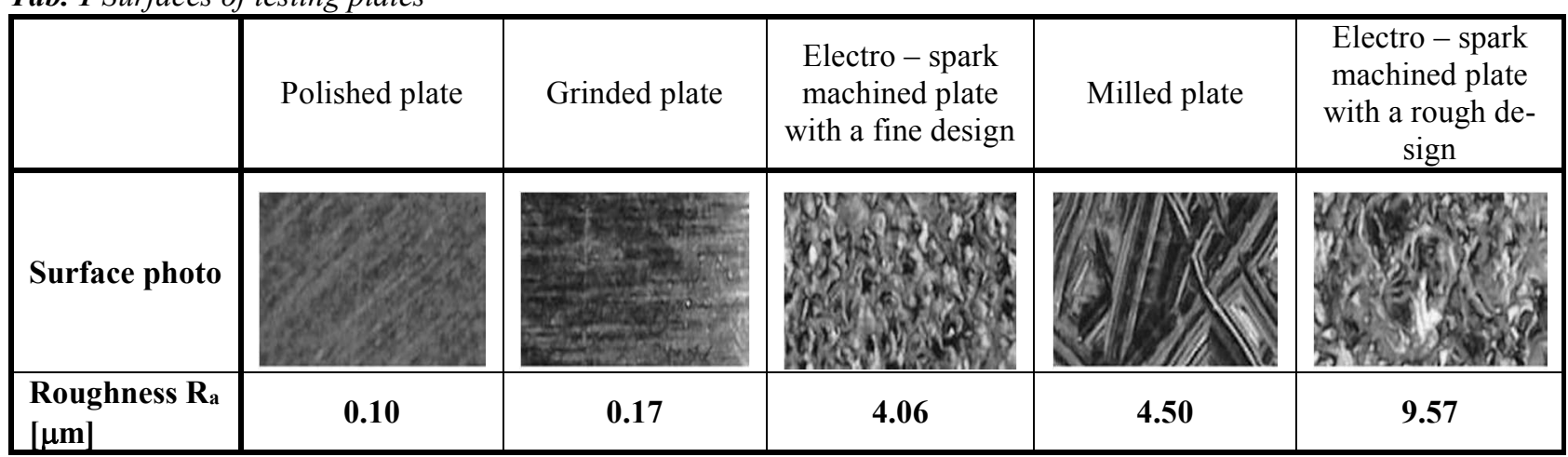

The surface of the plates was machined by four different technologies, which are most commonly used to work down the cavities of molds and runners in industrial production. These technologies are polishing, grinding, milling and two types of electro-spark machining - fine and rough design (Table 1). The surface roughness of all testing plates was measured on Talysurf CLI 500 by TaylorHobson. Scanned area was $4 \times 4 \mathrm{~mm}$. Pitch of points was set to $0.01 \mathrm{~mm}$.

The testing plates are made from tool steel(W.Nr. 1.2343) that are use for simple and fast change of the surface of the mold cavity. [7]

Injection molding machine ARBURG Allrounder 420C 1000 - 350 with oil tempering unit Regloplas 150 smart was used for testing samples production.

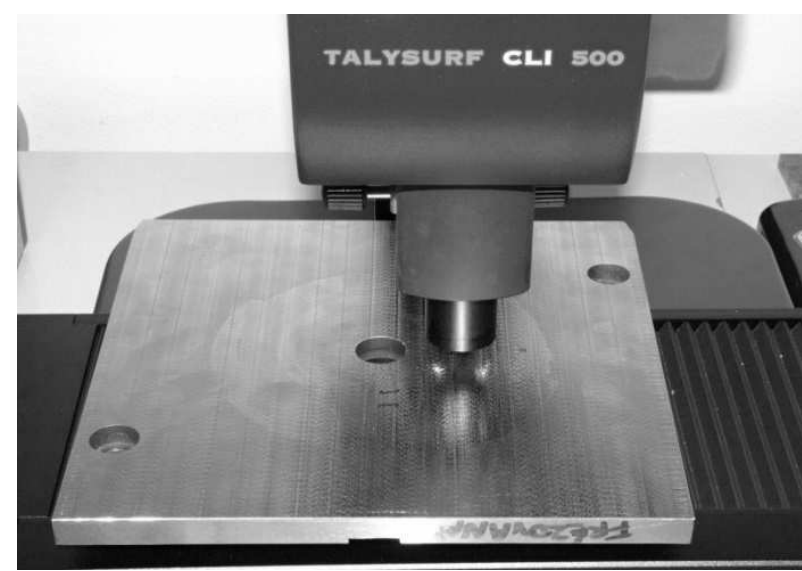

Fig. 4 Testing plate surface scanning by Talysurf CLI 500 


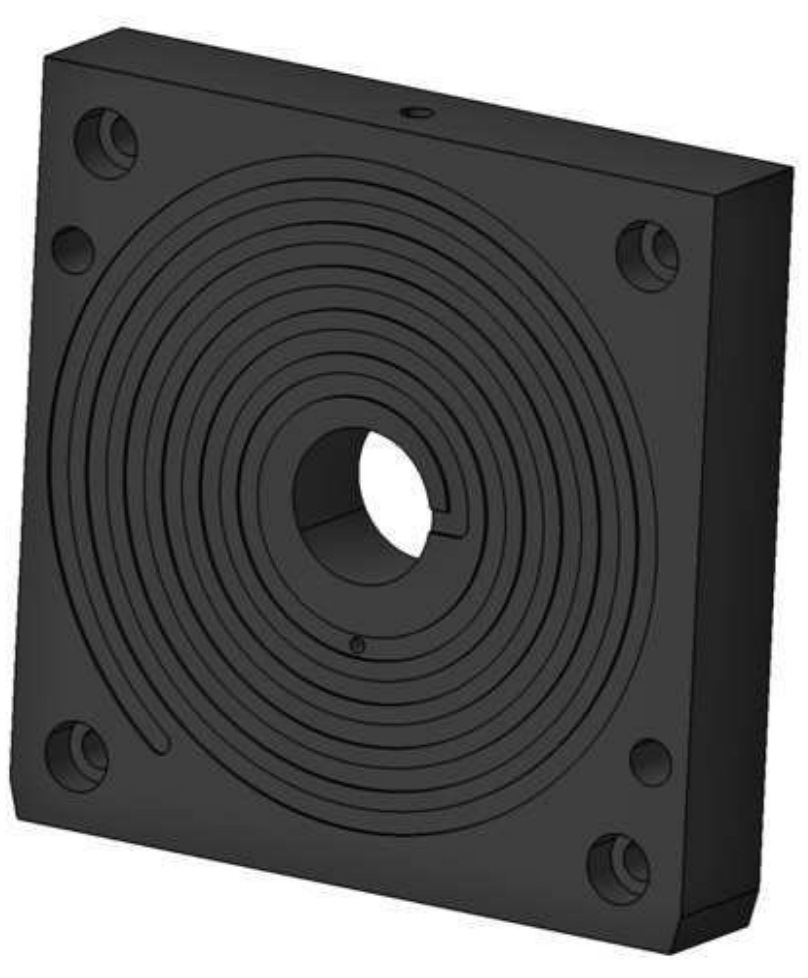

Fig. 5 Cavity plates: shaping plate (left) and testing plate (right)

\section{Tested polymers}

Four types of thermoplastic elastomers have been chosen for the fluidity testing. Thermoplastic polyurethane TPU form Bayer, specifically, it was Desmopan

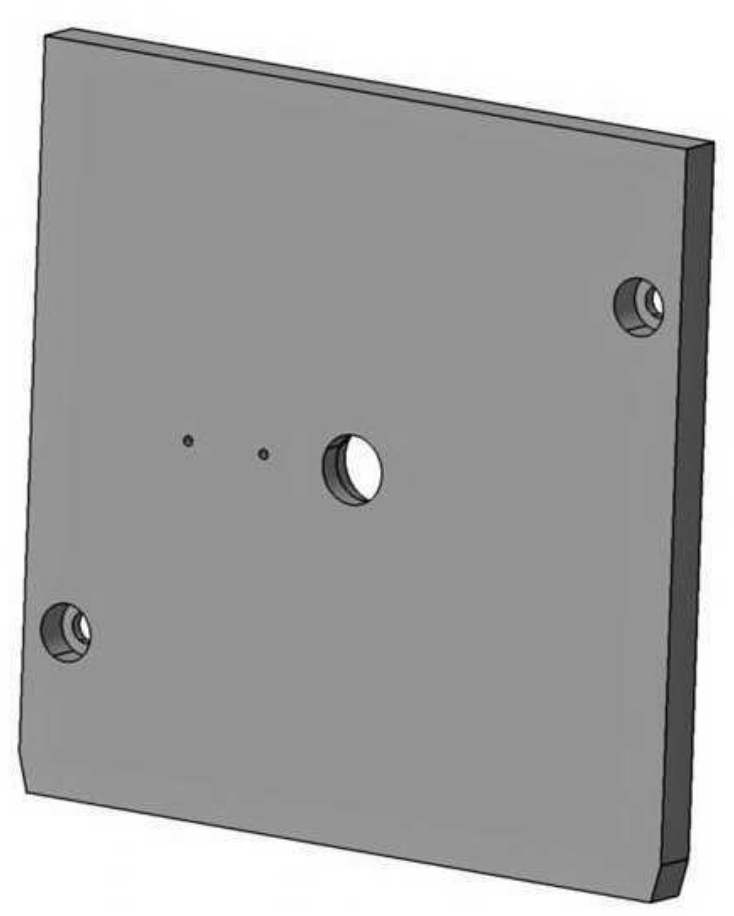

Tab. 2Selected material properties

\begin{tabular}{|c|c|c|c|c|c|c|}
\hline \multirow{3}{*}{ Material } & \multicolumn{2}{|c|}{ Melt Flow Index } & \multirow{2}{*}{$\begin{array}{c}\text { Density } \\
23^{\circ} \mathrm{C}\end{array}$} & \multirow{2}{*}{$\begin{array}{c}\text { Hardness } \\
\text { Shore A, D }\end{array}$} & \multirow{2}{*}{$\begin{array}{c}\text { Tensile Stren- } \\
\text { gth }\end{array}$} & \multirow{2}{*}{ Elongation } \\
\hline & Conditions & Value & & & & \\
\hline & ${ }^{\circ} \mathrm{C} / \mathrm{kg}$ & $\mathrm{g} / 10 \mathrm{~min}$ & $\mathrm{~kg} / \mathrm{m}^{3}$ & - & MPa & $\%$ \\
\hline TPU 372 & $230 / 2.16$ & 13.2 & 1240 & 98 & 70 & 250 \\
\hline TPE E 27 & $190 / 2.16$ & 8.6 & 1100 & 85 & 18.6 & 874 \\
\hline Hytrel 3078 & $190 / 2.16$ & 5 & 1070 & 30* & 24 & 740 \\
\hline Hytrel 7246 & $240 / 2.16$ & 12.5 & 1260 & $72 *$ & 53 & 450 \\
\hline
\end{tabular}

* Shore D

\section{Results}

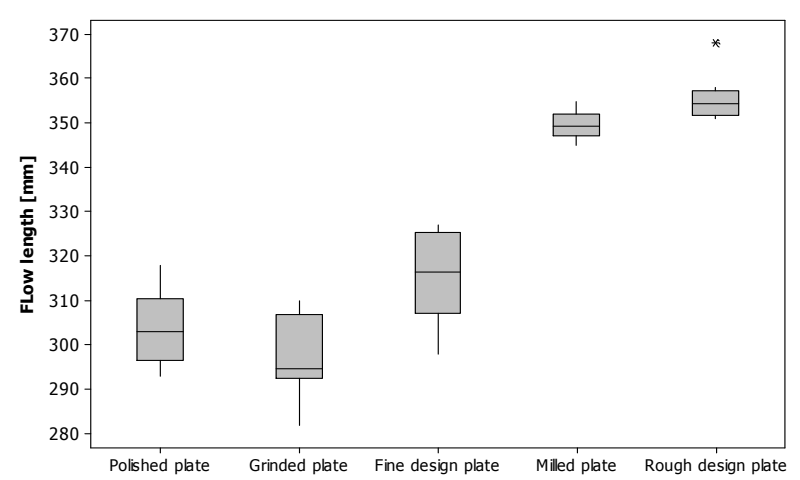

Fig. 6 Influence of the surface roughness on flow length (material TPU 372)
372 („TPU 372“). Three thermoplastic elastomers TPE,two from DuPont ("Hytrel 3078" a "Hytrel 7246") and one from PTS (v-pts-uniflex-e27d/M*M800/20) (,TPE E27“).

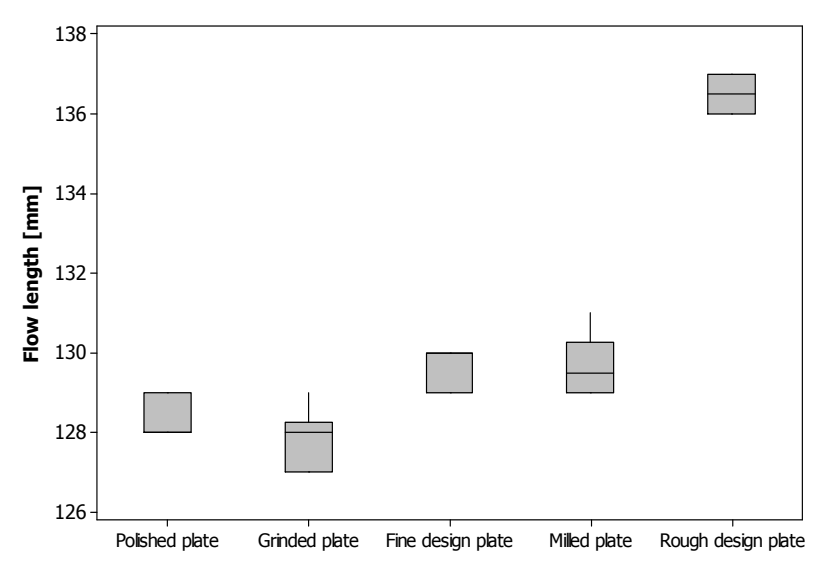

Fig. 7 Influence of the surface roughness on flow length (material TPE E27) 


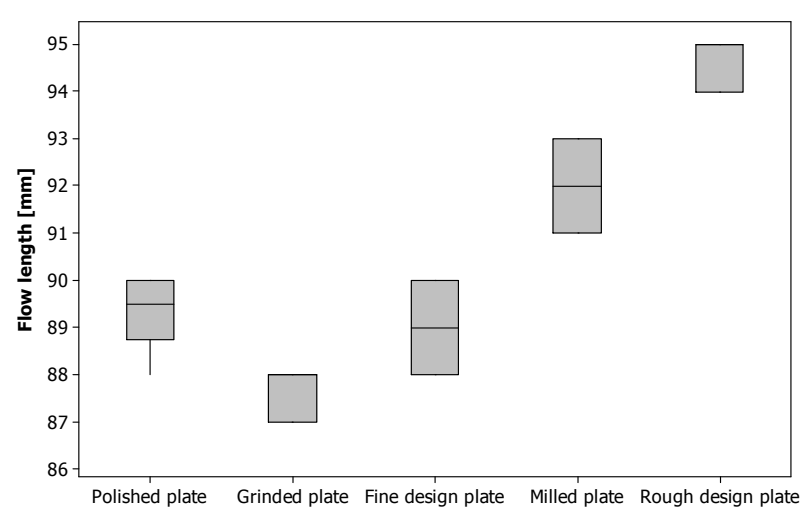

Fig. 8 Influence of the surface roughness on flow length (material Hytrel 3078)

The filling of mold cavity depends on material properties, technological conditions and surface quality. Very important result rises from experiments which analyzed the influence of surface quality on injection mold filling. It could be generally said that the surface quality of flow pathway significantly affects flow of polymer melt. It was found that better quality of wall surface worsened the flow condition and the length of injected sample spiral was shorter. This finding could have very important effect for tools producers. It is not necessary to use high precision cutting operation and it would be possible to exclude some very costly final operation as for example grinding or nolichino

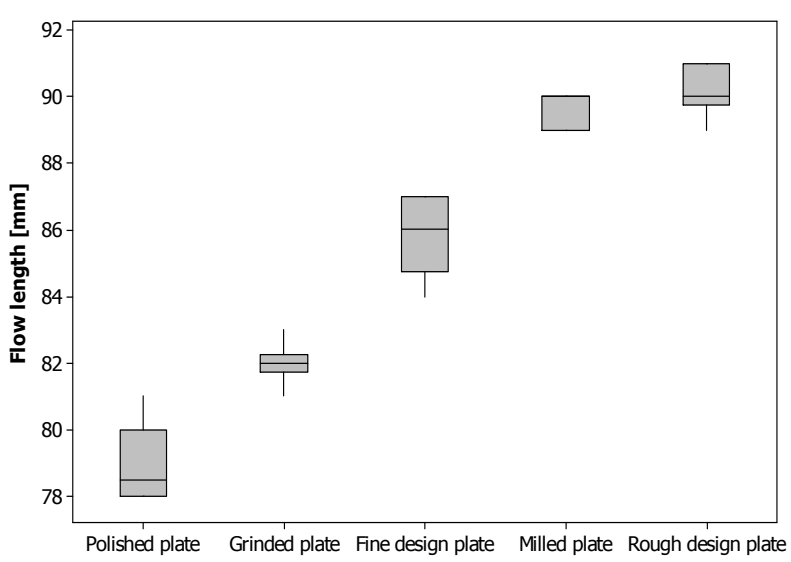

Fig. 9 Influence of the surface roughness on flow length (material Hytrel 7246)

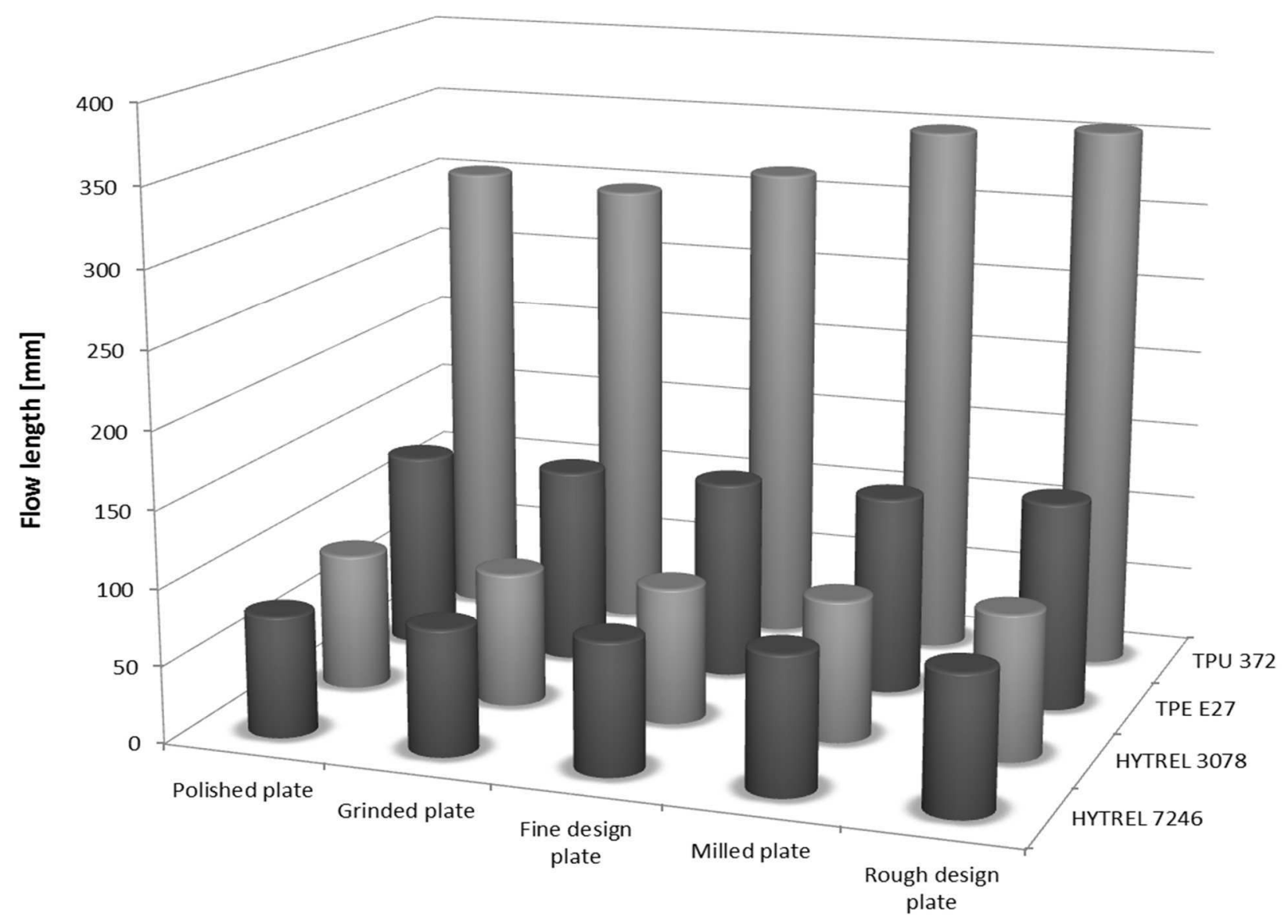

Fig. 10 Influence of the surface roughness on flow length (all materials)

\section{Conclusion}

This research looked in to the influence of technological parameters on filling of the injection mold cavity and the flow length respectively. The differences in flow lengths on the testing cavity plates with different surface roughness were very small, rather higher in case of testing plates with rougher surfaces of the mold.

The measurement shows that surface roughness of the injection mold cavity or runners have no substantial influence on the length of flow. This can be put directly into 
practice. It also suggests that final working and machining (e.g. grinding and polishing) of some parts of the mold, especially the flowing pathways (cold runner system), are not necessary.

\section{Acknowledgment}

This work was supported by the European Regional Development Fund under the project CEBIA-Tech Instrumentation No. CZ.1.05/2.1.00/19.0376 and by the Ministry of Education, Youth and Sports of the Czech Republic within the National Sustainability Program project no. LO1303 (MSMT-7778/2014). Moreover, it was supported by the Internal Grant Agency of TBU in Zlin: no. IGA/FT/2019/002.

\section{References}

[1] MANAS, M., HRIBOVA, M., MANAS, M., OVSIK, M., STANEK, M. SAMEK, D. (2012). The effect of beta irradiation on morfology and micro hardness of polypropylene thin layers, Thin Solid Films, Volume 530, pp. 49-52. ISSN 00406090.

[2] STANEK, M., MANAS, D., MANAS, M., SUBA, O.(2011). Optimization of Injection Molding Process, International Journal of Mathematics and Computers in Simulation, Volume 5, Issue 5, p. 413-421.

[3] STANEK, M., MANAS, D., MANAS, M., JAVORIK, J. (2011). Simulation of Injection Molding Process by Cadmould Rubber, International Journal of Mathematics and Computers in Simulation, Volume 5, Issue 5, p. 422-429.

[4] MANAS, D.,MANAS, M.,STANEK, M.,SANDA, S., PATA, V. (2011). Thermal Effects on Steels at Different Methods of Separation, Chemicke listy, Volume 105, Issue 17, pp. S713-S715.

[5] MANAS, M., MANAS, D.,STANEK, M.,SANDA, S., PATA, V.(2011). Improvement of Mechanical Properties of the TPE by Irradiation, Chemicke listy, Volume 105, Issue 17, pp. S828-S829.

[6] JAVORIK, J., STANEK, M. (2011). The Shape Optimization of the Pneumatic Valve Diaphragms, International Journal of Mathematics and Computers in Simulation, Volume 5, Issue 4, p. 361-369.

[7] STANEK, M, MANAS, M., MANAS, D., SANDA, S. (2009). Influence of Surface Roughness on Fluidity of Thermoplastics Materials, Chemicke listy, Volume 103, pp.91-95.

[8] MANAS, D., STANEK, M., MANAS, M., PATA V., JAVORIK, J., (2009). Influence of Mechanical Properties on Wearof Heavily Stressed Rubber Parts, KGK - KautschukGummiKunststoffe, 62. Jahrgang, p.240-245.

[9] STANEK, M., MANAS, M., MANAS, D., SANDA, S. Influence of Surface Roughness on Fluidity of Thermoplastics Materials, Chemicke listy, Volume 103, p.91-95.

[10] MANAS, M., STANEK, M., MANAS, D., DANEK, M., HOLIK, Z. (2009). Modification of polyamides properties by irradiation, Chemické listy, Volume 103, p.24-26.

[11] MANAS, D., MANAS, M., STANEK, M., ZALUDEK, M., SANDA, S., JAVORIK, J., PATA, V. (2009). Wear of Multipurpose Tire Treads, Chemické listy, Volume 103, p.72-74.

[12] SANDA, S., MANAS, M., STANEK, M., MANAS, D., ROZKOSNY, L. (2009). Injection Mold Cooling System by DMLS, Chemicke listy, Volume 103, p.140-142.

[13] EPERJESI, S., MATVIJA, M., BARTOSOVA, M., FECKO, D., PRIBULOVA, A. (2017). Effect of Heat Treatment Conditions on Micro Structure of Cast Iron. In: Manufacturing Technology, Vol. 17 , pp. 29-33.

[14] MULLER, M. (2017). Effects of Aluminium Microparticles and Surface Treatment of AlCu4Mgon Mechanical Properties of Adhesive Bond Strength. In: Manufacturing Technology, Vol. 17, pp. 66-71.

[15] OVSIK, M., STANEK, M., HYLOVA, L., MANAS, M., STOKLASEK, P. (2019) The thermal energy influence on the surface layer of construction steels during laser beam cutting. In: $M a$ nufacturing Technology, Vol. 19 (1), pp. 123-128. 